\title{
REVIEW
}

\section{Haematological cancer and quality of life: a systematic literature review}

\author{
P Allart-Vorelli ${ }^{1}$, B Porro ${ }^{2}$, F Baguet ${ }^{2,3}$, A Michel $^{2,4}$ and F Cousson-Gélie ${ }^{2,3}$
}

The aim of this study is to examine the impact of haematological cancers on quality of life (QoL). A review of the international literature was conducted from the databases 'Psyclnfo' and 'Medline' using the keywords: 'haematological cancer', 'quality of life', 'physical', 'psychological', 'social', 'vocational', 'professional', 'economic', 'cognitive', and 'sexual'. Twenty-one reliable studies were analysed. Among these studies, 12 showed that haematological cancer altered overall QoL, 8 papers found a deterioration of physical dimension, 8 papers reported on functional and role dimensions, 11 papers reported on the psychological component and 9 on the social component. Moreover, one study and two manuscripts, respectively, reported deteriorated sexual and cognitive dimensions. Our review demonstrates that the different dimensions of QoL are deteriorated by haematological malignancies and, probably, by the side effects of treatment.

Blood Cancer Journal (2015) 5, e305; doi:10.1038/bcj.2015.29; published online 24 April 2015

\section{INTRODUCTION}

Haematological cancers include various diseases (Hodgkin's lymphoma, non-Hodgkin's lymphoma, leukaemia and multiple myeloma. The term leukaemia comprises acute myeloid leukaemia, chronic myelogenous leukaemia, acute lymphoblastic leukaemia and chronic lymphoblastic leukaemia); they can affect children, young adults and the elderly, and their incidence increases with age. ${ }^{1}$ As liquid tumours moving in the blood or lymph, acute or chronic diseases, with side effects induced by different treatments, are unique. Just as these diseases are distinct entities showing many differences from solid tumours, so too is the manner in which they are managed. ${ }^{2}$ In 1999, leukaemias and lymphomas accounted for approximately $8 \%$ of all cancers in adults. ${ }^{3}$ The 5 -year survival rates vary from $47 \%$ to $95 \%$ depending on the malignancy. ${ }^{4}$

Quality of life (QoL) is usually impaired in the elderly: the biological nature and course of treatment of haematological cancer differ among children and adults, ${ }^{5-7}$ with long-term survival outcomes favouring young people diagnosed and treated as children. ${ }^{3}$

Our paper also focuses on health-related QoL (QoL), a factor reflecting the individual's assessment of his/her life at any one time relative to his/her previous state and prior experience. ${ }^{8}$ Health-related QoL is multidimensional and temporal, relating to a state of functional, physical, psychological and social/family well-being. ${ }^{9}$ Compared with the general population, the health-related QoL of cancer patients is worse in most dimensions. ${ }^{10,11}$

This review describes the QoL and the different problems that patients with haematological malignancies encounter.

\section{MATERIALS AND METHODS}

\section{Search strategy}

A review was conducted from databases 'Psyclnfo' and 'Medline', searching for studies published between 1990 and 2011 with keywords: 'haematological cancer', 'quality of life', 'physical', 'psychological', 'social', 'vocational', 'professional', 'economic', 'cognitive', and 'sexual' appearing in the abstracts.

We used nine combinations for all databases: (1) 'QoL and haematological cancer', (2) 'haematological cancer and physical', (3) 'haematological cancer and psychological', (4) 'haematological cancer and social', (5) 'haematological cancer and cognitive', (6) 'haematological cancer and economic', (7) 'haematological cancer and professional', (8) 'haematological cancer and vocational', and (9) 'haematological cancer and sexual'.

Criteria for inclusion/exclusion. Prospective, comparative, exploratory, longitudinal or cross-sectional studies, assessing the QoL or health-related QoL, were analysed. Papers focusing on lymphoma, leukaemia or myeloma patients with chemotherapy, radiotherapy or blood transfusion in periods of remission or relapse were included. However, retrospective studies with other forms of cancer and reviews of the literature were excluded.

Quality assessment and levels of evidence. The studies had to be based on reliable methodological procedure (large population study, standardized tools and relevant statistical methods) and meet the criteria of a table that describes five levels of evidence (Level I: high-quality prospective study (all patients were enrolled at the same point in their disease with $80 \%$ follow-up of patients); Level II: retrospective study, untreated controls from a randomized control trial, lesser prospective study (patients enrolled at different

\footnotetext{
${ }^{1}$ Laboratory of Psychology 'Health and Quality of Life' EA 4139, University Bordeaux Segalen, Bordeaux, France; ${ }^{2}$ Department of Psychology, Epsylon EA 4556 Laboratory 'Dynamics of Human Abilities and Health Behaviors', University Paul Valéry Montpellier 3, Montpellier, France; ${ }^{3} \mathrm{ICM}$, Institut Régional du Cancer de Montpellier, Epidaure Prevention Unit - Rue des Apothicaires, Montpellier Cedex 5, France and ${ }^{4}$ MIS, Montpellier Institut du Sein - 25 rue de Clémentville, Montpellier, France. Correspondence: B Porro, Department of Psychology, Epsylon EA 4556 Laboratory 'Dynamics of Human Abilities and Health Behaviors', University Paul Valéry Montpellier 3, Route de Mende, Montpellier F-34199, France. 
points in their disease or $<80 \%$ follow-up); Level III: case control study; Level IV: case series; Level V: expert opinion) in prognostic studies (investigating the effect of a patient's characteristic on the outcome of the disease). ${ }^{12}$ We considered only level I and II studies.

Data synthesis. Studies were analyzed by dimensions of QoL and symptoms (description of QoL in Table 1).

\section{RESULTS}

Article identification

In total, 82 studies emerged: 73 studies for 'Psyclnfo' and 9 studies for 'Medline'. There were 21 studies for combination 1, 14 for combination 2, 14 for combination 3, 9 for combination 4, 11 for combination 5, 3 for the combination 6,10 for the combination 7 and 0 for the combinations 8 and 9 . By limiting inclusion to studies that provided evidence of the impact of cancer on QoL, we selected 21 studies.

Methodological characteristics. One paper presented the level of evidence $\mathrm{I}^{13}$ and 20 level II. ${ }^{14-33}$ Twelve were comparative, ${ }^{14-18,20,23-24,26,28,30,32,34} 5$ were longitudinal, ${ }^{14,19,20,22,33}$ 5 were cross-sectional, ${ }^{21,23,24,26,27} 2$ were descriptive, ${ }^{16,17} 2$ were pilot $_{1}^{25,29} 1$ was prospective, ${ }^{23} 1$ was retrospective, ${ }^{31} 1$ was international ${ }^{28}$ and 1 was a web-based survey. ${ }^{28}$

Patient population. In total, 7349 patients (3987 patients with lymphoma, 2303 with leukaemia, 711 with myeloma, 6 patients with amyloidosis and 1 with myelofibrosis; 341 no specified patients) were included in the studies (average age of 54.8 years).

One study focussed on the cognitive functioning of lymphoma patients by comparing two groups (test group and no-test group (diagnosis unknown). ${ }^{15}$ Another paper examined the QoL, without specifying the number of patients per diagnosis. ${ }^{33}$ The healthrelated QoL was studied in acute lymphoblastic leukaemia, myelofibrosis or unclassified leukaemia patients, but the authors did not specify the sample size of patients per diagnosis. ${ }^{21}$ There were 1171 control groups with haematological patients and healthy subjects in 3 studies. $^{20,26,32}$

QoL and health-related QoL of haematological cancer patients Overall QoL. Twelve papers showed that haematological cancer negatively affect overall QoL and health-related QoL. ${ }^{13,14,16,18,20,22,24,25,27,28,30,31}$ We noted a strong association between anaemia and QoL in lymphoma patients before chemotherapy. ${ }^{22}$ We found an impairment of QoL in multiple myeloma patients at diagnosis, ${ }^{18}$ at the beginning of treatment ${ }^{13}$ and during treatment, ${ }^{27}$ in chronic lymphoblastic leukaemia patients with chemotherapy ${ }^{16}$ and in multiple myeloma and acute lymphoblastic leukaemia patients at the start of chemotherapy. ${ }^{25}$ The latter study found that QoL was more deteriorated in patients with relapses, in comparison to patients who had no relapse, even at the onset of treatment. Moreover, QoL was worse in patients with an advanced stage of disease. ${ }^{28}$

Chronic lymphoblastic leukaemia patients had impaired healthrelated QoL compared with the general population. ${ }^{16}$ Compared with healthy controls, chronic lymphoblastic leukaemia patients with chemotherapy reported a lower QoL. ${ }^{20}$ Non-Hodgkin's lymphoma survivors with active disease presented a worse QoL compared with short- or long-term survivors. ${ }^{30}$ Moreover, one paper found a better QoL in Hodgkin's lymphoma survivors diagnosed 10-15 years previously than patients diagnosed 5-9 years ago. ${ }^{24}$

QoL improved after aerobic exercise training programme ${ }^{14}$ and was better in non-Hodgkin's lymphoma patients meeting public health exercise guidelines, compared with those who did not. ${ }^{31}$
Nevertheless, one study found that QoL of chronic lymphoblastic leukaemia patients was similar to or better than published population. ${ }^{28}$ However, one study demonstrated that QoL improved during and after chemotherapy in aggressive nonHodgkin's lymphoma patients. ${ }^{22}$

General health. Five reports investigated the general health in haematological population. ${ }^{14,17,22-24}$ For multiple myeloma and non-Hodgkin's lymphoma patients, their physical health and mobility were the most frequent domains affected by the disease. $^{17}$ Two studies noted that non-Hodgkin's lymphoma patients had a worse general health and that Hodgkin's lymphoma survivors presented lower general health compared with the population. ${ }^{23,24}$ In another study comparing general health in patients treated with usual care or aerobic exercise training programme, aerobic exercise training patients had better general health than the other patients. ${ }^{14}$ However, after chemotherapy, general health improved in non-Hodgkin's lymphoma patients in one study. ${ }^{22}$

Physical dimension. Eight studies showed that haematological cancer deteriorates the physical component of QoL. ${ }^{14,18,19,20,21,24,29,30}$ Some patients negatively perceived their physical well-being after bone marrow transplanation. ${ }^{19}$ Four other studies showed that physical function was affected in multiple myeloma patients ${ }^{17,18,21,29}$ and that older patients presented more reduced physical functioning than younger patients. ${ }^{21}$ Non-Hodgkin's lymphoma survivors with active disease demonstrated worse physical functioning compared with disease-free survivors and population. ${ }^{30}$ Aerobic exercise training programme patients had better cardiovascular fitness than usual care patients. ${ }^{14}$ Long-term Hodgkin's lymphoma survivors diagnosed 10-15 years earlier reported better physical functioning than survivors diagnosed 5-9 years before. ${ }^{24}$ For chronic lymphoblastic leukaemia patients, physical functioning was significantly deteriorated compared with the healthy controls. ${ }^{20}$

Fatigue, lack of vitality and energy: Ten papers found that fatigue was one of the most prevalent symptoms experienced in haematological patients. ${ }^{14-16,18,20,21,25,26,29,32}$ Compared with population, chronic lymphoblastic leukaemia patients had impaired health-related QoL for fatigue. ${ }^{16}$ For $55 \%$ of haematological patients, fatigue was the main symptom with insomnia, ${ }^{21}$ in particular in acute leukaemia and highly malignant lymphoma patients. ${ }^{25}$ One paper reported that levels of fatigue in Hodgkin's lymphoma and chronic lymphoblastic patients were higher than patients in healthy controls, even for years after treatment. ${ }^{20}$ Having severe illnesses in Hodgkin's lymphoma survivors was positively associated with fatigue. ${ }^{26}$ Another study showed that lymphoma patients who reported concentration and memory difficulties demonstrated much fatigue; ${ }^{15}$ symptom less pronounced in aerobic exercise training programme patients compared with usual care patients. ${ }^{14}$ These findings are consistent with the results found in another report. ${ }^{18,29}$

Three studies noted that patients with bone marrow transplanation, ${ }^{19}$ Hodgkin's lymphoma survivors treated by radiotherapy or chemotherapy ${ }^{32}$ and Hodgkin's lymphoma survivors ${ }^{24}$ presented a lack of energy. For vitality, patients diagnosed 5-9 years before presented a greater lack of vitality than those diagnosed 10-15 years before. ${ }^{24}$ Finally, non-Hodgkin's lymphoma patients reported less vitality compared with population. ${ }^{23}$

Pain: Painful sensations were frequent in haematological patients for five studies. ${ }^{18,21-23,29}$ Pain was the most distressing problem for multiple myeloma, ${ }^{18}$ monoclonal gammopathy of unknown significance (MGUS) ${ }^{29}$ and leukaemia and lymphoma patients. ${ }^{21}$ In the latter study, older patients had more pain than younger patients. Similar results were found in non-Hodgkin's lymphoma patients who reported more bodily pain than the general population. ${ }^{23}$ However, during chemotherapy, less pain 


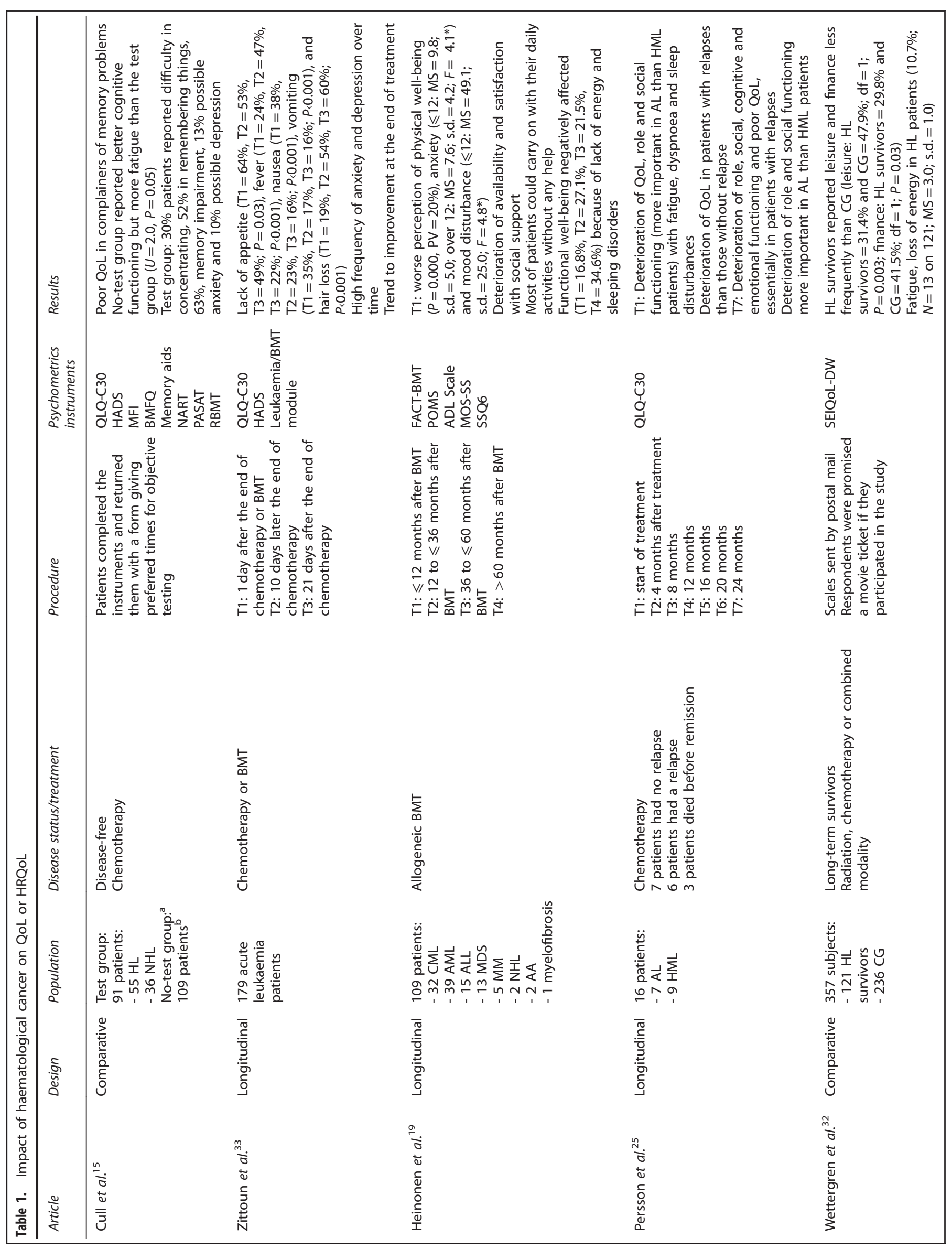




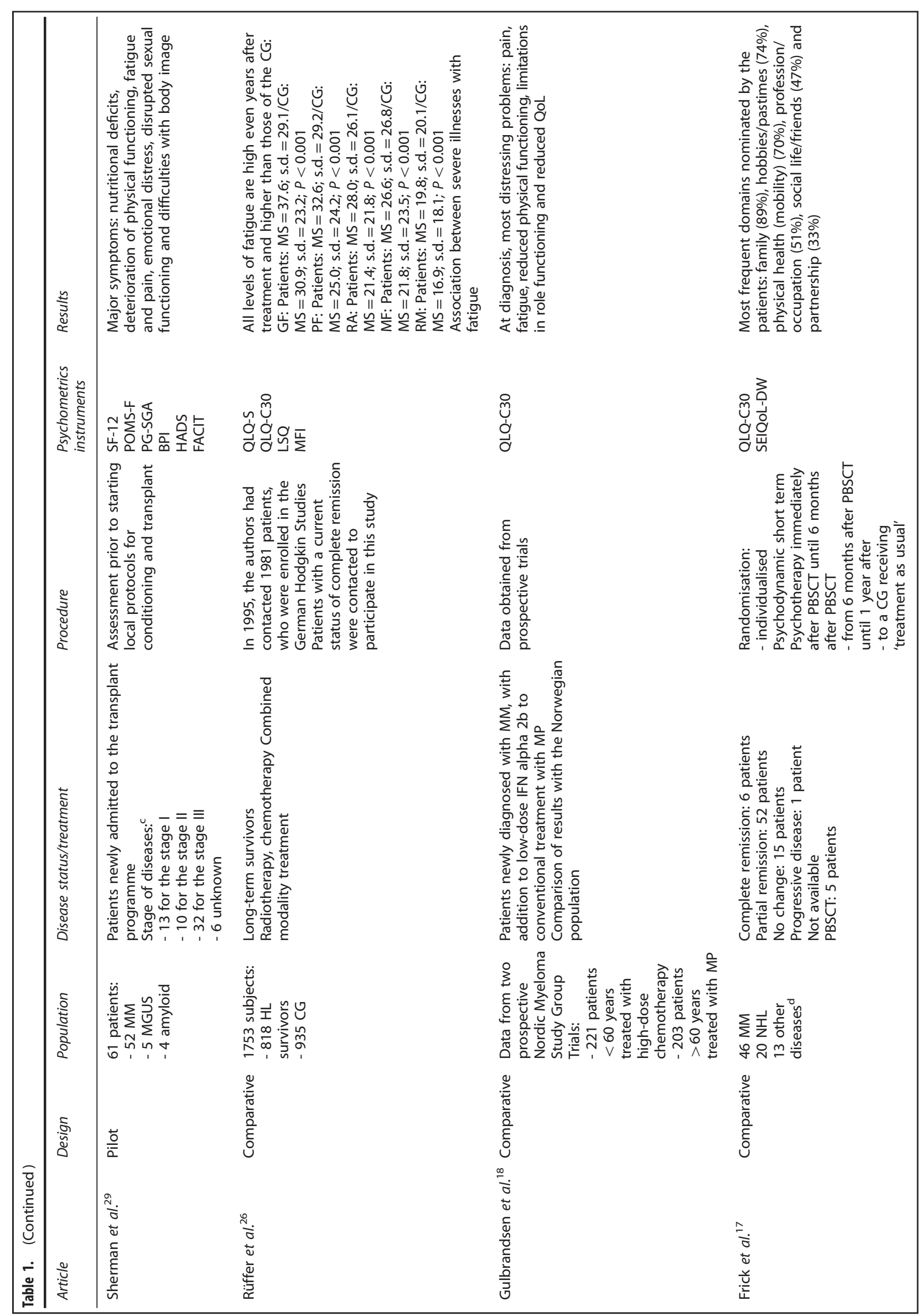




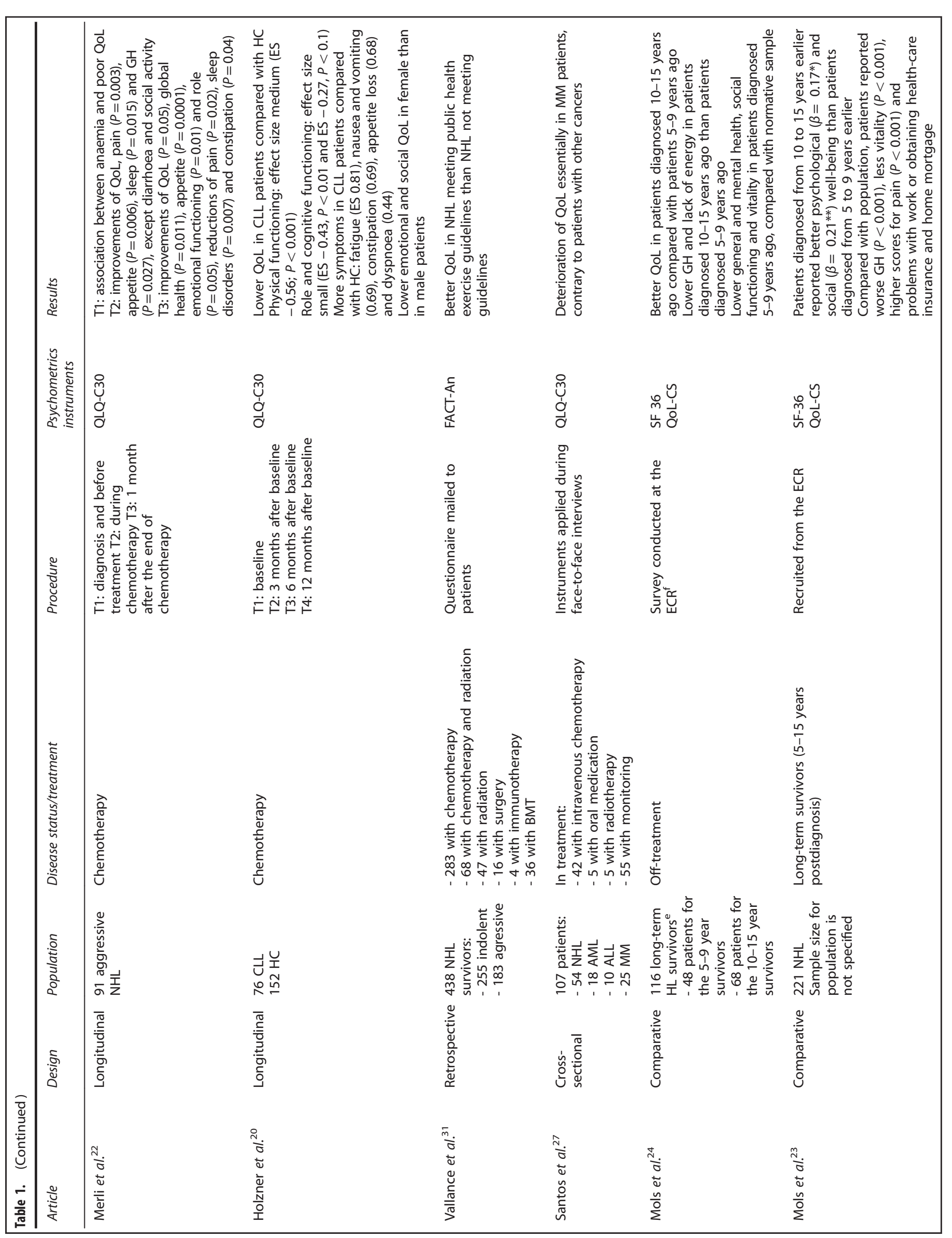




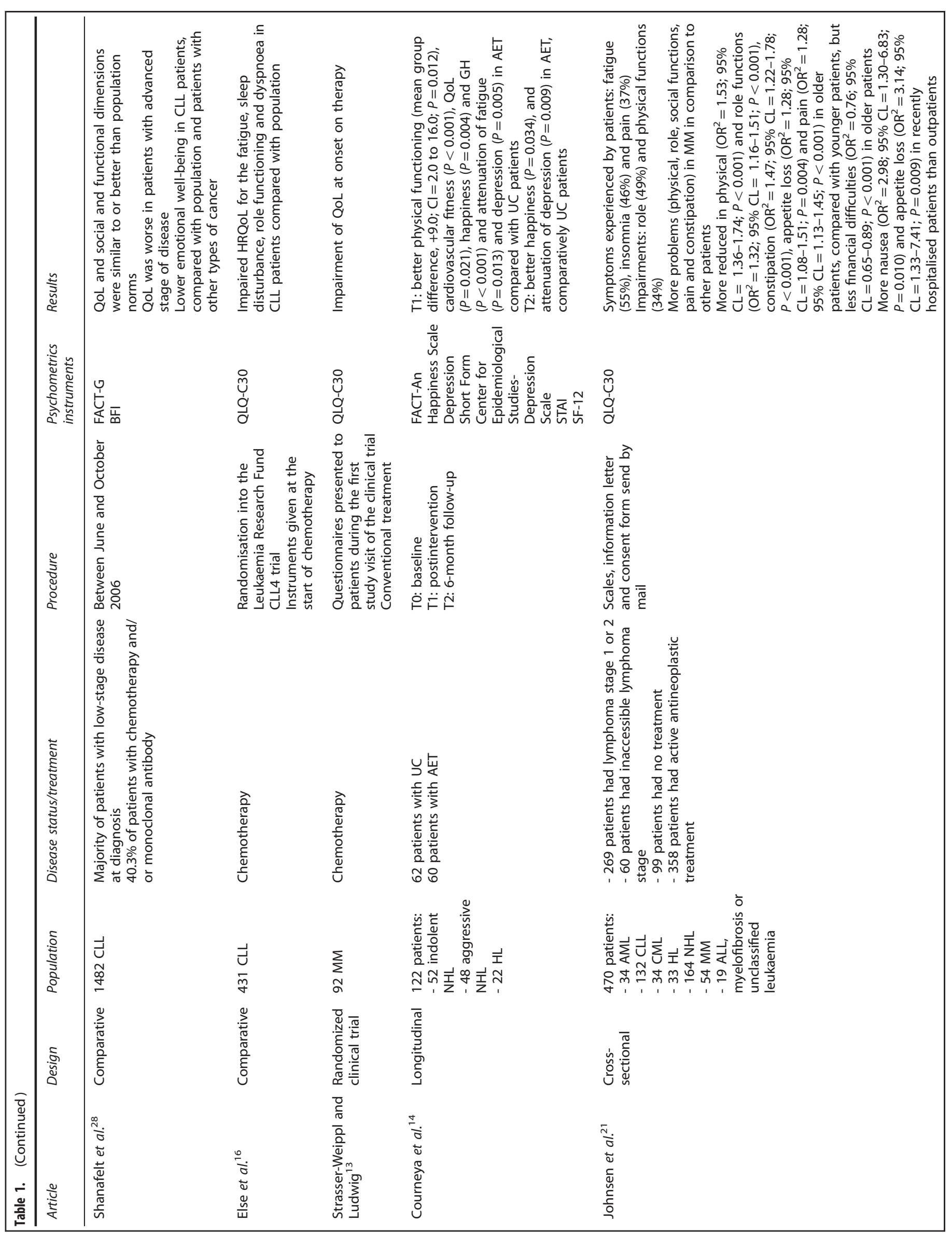




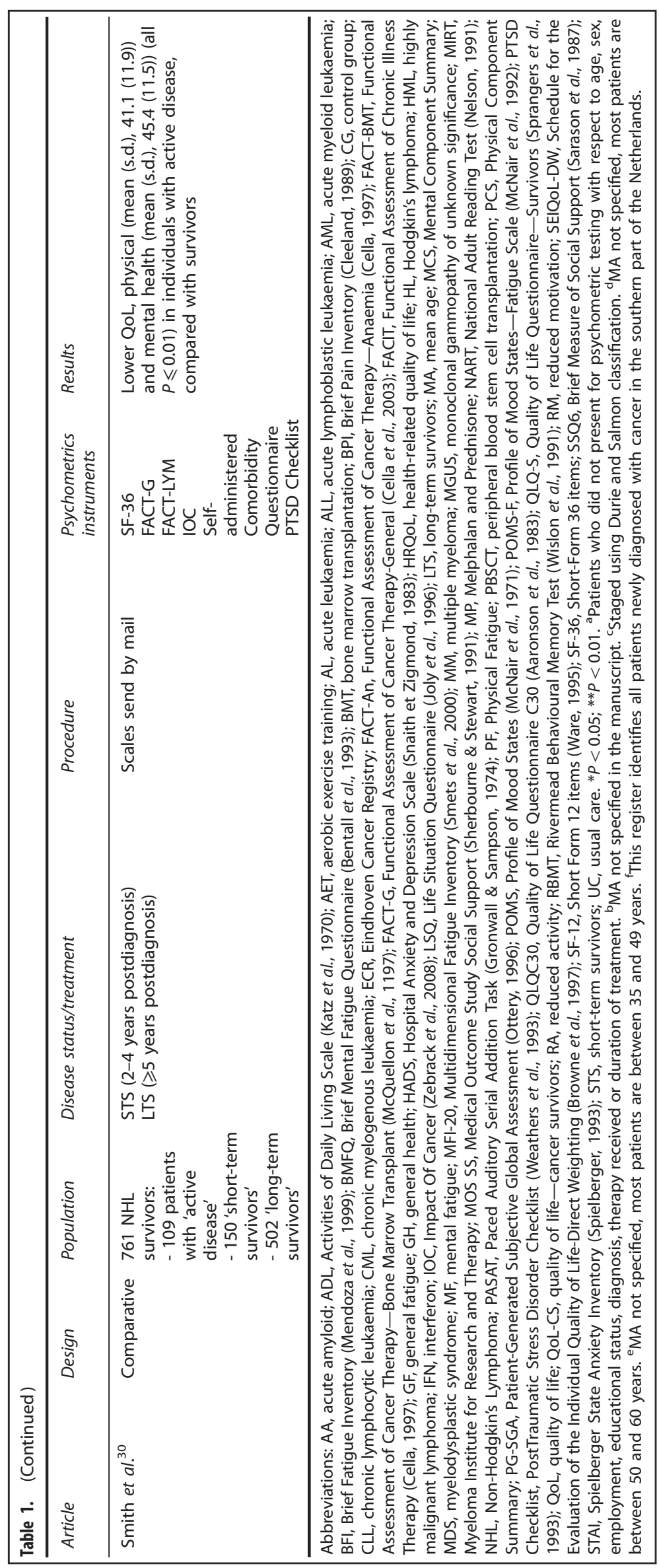


was experienced by aggressive non-Hodgkin's lymphoma patients in only one study. 22

Sleep disorders: Four studies found that sleep was affected by haematological cancer. ${ }^{16,19,22,25}$ Sleep disorders were prevalent in acute leukaemia and highly malignant lymphoma patients at the start of treatment. ${ }^{25}$ Compared with the general population, chronic lymphoblastic leukaemia patients presented more sleep disorders, ${ }^{16}$ related to functional well-being. ${ }^{19}$ An improvement was found in sleep disturbances during and after chemotherapy in aggressive non-Hodgkin's lymphoma patients. ${ }^{22}$

Digestive symptoms: Digestive symptoms may occur during haematological disease in four studies. ${ }^{20,21,22,33}$ Among the most common problems in acute leukaemia patients, we found lack of appetite, weight loss, nausea and vomiting, 1 day after the end of chemotherapy or bone marrow transplanation. However, these symptoms had improved 10 and 21 days after the end of treatment. ${ }^{33}$ Older and recently hospitalised patients had more constipation, nausea and loss of appetite than younger patients and outpatients. ${ }^{21}$ Moreover, non-Hodgkin's lymphoma patients presented diarrhoea during chemotherapy but showed constipation 1 month after the end of treatment. ${ }^{22}$ Finally, chronic lymphoblastic leukaemia patients showed more nausea and vomiting, constipation and appetite loss than healthy controls. ${ }^{20}$ Dyspnoea: In three studies, dyspnoea, predominant with chemotherapy, was one of the most common symptoms in acute leukaemia and highly malignant lymphoma patients ${ }^{25}$ and in chronic lymphoblastic leukaemia patients. ${ }^{16,20}$

Nutrition: In one study, nutritional deficits predominated in multiple myeloma and MGUS patients, treated with transplant. ${ }^{29}$ Fever: Only one study mentioned the problem of fever in acute leukaemia during chemotherapy. ${ }^{33}$

Functional and role dimensions. Two studies focussed on the functional dimension, ${ }^{19,28}$ negatively affected after a bone marrow transplanation. However, in one study could most patients carry on with their daily activities without any help 1 year after bone marrow transplanation. ${ }^{19}$ Moreover, some authors found that daily functioning was similar or better than the population norms. ${ }^{28}$

Concerning role, six studies focussed on this dimension. ${ }^{16,18,20-22,25}$ One study analysed the deterioration of role function in leukaemia, multiple myeloma or lymphoma patients. ${ }^{21}$ Role was affected in leukaemia and lymphoma ${ }^{25}$ and multiple myeloma patients, ${ }^{18}$ essentially in older patients. Compared with the general population, chronic lymphoblastic lymphoma patients had impaired role functioning for two studies. ${ }^{16,20}$ However, improvement of role was observed 1 month after the end of chemotherapy in non-Hodgkin's lymphoma patients. ${ }^{22}$

Psychological dimension. Eleven studies showed that haematological cancers affect psychological QoL. ${ }^{14,15,19,20,23,24,28-30,32,33}$ One paper found that patients diagnosed 10-15 years earlier reported better psychological well-being than patients diagnosed 5-9 years ago. ${ }^{23}$ Lymphoma patients with chemotherapy presented possible anxiety and depression ${ }^{15}$ and we noted a high frequency of anxiety and depression in acute leukaemia patients, with a trend to improvement at the end of treatment. ${ }^{33}$ One study suggested that patients experienced more anxiety and mood disturbance after bone marrow transplanation compared with those with a longer follow-up. ${ }^{19}$ Hodgkin's lymphoma or nonHodgkin's lymphoma patients receiving aerobic exercise training programme reported less depression and greater happiness compared with those who did not participate in the programme. ${ }^{14}$ Individuals with active disease demonstrated worse mental health functioning compared with population and diseasefree survivors. ${ }^{30}$ Additional studies reported that emotional distress was present in multiple myeloma, MGUS, amyloid ${ }^{29}$ and chronic lymphoblastic leukaemia patients. ${ }^{20}$ Finally, chronic lymphoblastic leukaemia patients presented lower emotional well-being compared with the general population. ${ }^{24,28}$ Moreover, Hodgkin's lymphoma survivors presented a different and positive vision of life after disease. ${ }^{32}$

Cognitive dimension. Two papers focussed on the cognitive functioning. ${ }^{15,20}$ The cognitive area was significantly deteriorated in chronic lymphoblastic leukaemia patients, compared with healthy controls, ${ }^{20}$ and lymphoma patients with memory problems had a lower QoL. ${ }^{15}$

Social, professional and economic dimensions. Nine papers showed that social, professional and financial QoL were affected by haematological cancer. ${ }^{17,19-21,23-25,28,32}$ One report found a deterioration of social functioning in leukaemia and lymphoma patients with chemotherapy. ${ }^{25}$ Chronic lymphoblastic leukaemia patients presented a lower social QoL, mainly women. ${ }^{20}$ Another study found the same finding in patients diagnosed 5-9 years earlier compared with patients diagnosed $10-15$ years before. ${ }^{24}$ In one study, the availability of, and satisfaction with, social support declined after bone marrow transplanation. ${ }^{19}$ The domain of family was affected in $89 \%$ of haematological patients. ${ }^{17}$ However, in one paper, the social functioning of chronic lymphoblastic leukaemia patients was similar to or better than that of the general population. ${ }^{28}$

Furthermore, one paper showed that Hodgkin's lymphoma survivors mentioned the topics of leisure and finance less frequently than controls. ${ }^{32}$ Older patients had fewer financial difficulties than outpatients, and multiple myeloma patients had a worse social QoL compared with those with other haematological cancers. $^{21}$ Finally, most frequent domains mentioned were hobbies/pastimes, partnerships, profession and social life and friends $s^{17}$ and difficulties to obtain health-care insurance and life insurance. $^{23}$

Sexual dimension. One study focussed on the sexual component ${ }^{29}$ and found that multiple myeoloma or MGUS patients presented sexual difficulties associated with body image. $^{29}$ The problem of body image could be associated with hair loss mentioned in another paper. ${ }^{33}$

\section{DISCUSSION}

The general findings show that the haematological disease negatively affects overall QoL. ${ }^{13,14,16,18,20,22,24,25,27,28,30,31}$ Compared with the general population, fatigue, pain or vitality were the more exposed ${ }^{35,36}$ aspects of QoL, which were specifically deteriorated during an advanced stage of haematological cancer. ${ }^{28}$ Compared with the general population, haematological patients had an adverse general health. ${ }^{23}$ These results confirm other findings concerning cancer populations. ${ }^{37}$

Fatigue was the most prevalent physical symptom. ${ }^{14-16,18,21,25,26,29,32,33}$ Most of the samples included elderly patients, and the progressive loss of autonomy in older people is not conducive to maintaining physical QoL. Haematological patients were more susceptible to fatigue than others because of the comorbidity and side effects due to treatment. ${ }^{38}$ Moreover, the benefits of physical programme on physical well-being were demonstrated. ${ }^{27}$ Similar data were found in Hodgkin's lymphoma survivors, an improvement in physical functioning and cardiovascular fitness being observed after exercise. ${ }^{39}$ The other physical symptoms were common to patients with other forms of cancers ${ }^{40}$ as well as breast cancer patients. ${ }^{41,42}$

Only one study found that haematological patients can manage acts of daily life without the need for support after bone marrow transplanation. ${ }^{19}$ However, older and multiple myeloma patients experienced more reduced role function than younger patients and subjects with other diagnoses. ${ }^{21}$ Indeed, the multiple myeloma patients were older than patients with other diagnoses, 
and advanced age proved to be a predictor of symptoms. Role was more affected in haematological patients than in the general population. ${ }^{16}$ Because of physical disabilities, it is plausible that familial or social missions were disturbed.

Mostly, psychological QoL was found to be worse. $^{14,15,19,20,23,24,28-30,32,33}$ One study noted that aerobic exercise training programme helped maintain good mental QoL. ${ }^{27}$ This may be due to the involvement of social interaction and a process of being distracted from one's cancer and treatments, a finding already made in advanced cancer patients. ${ }^{43}$ Moreover, emotional benefits occurred after patients with breast cancer followed a sports programme. ${ }^{44}$

Furthermore, haematological cancer damaged social, professional and financial QoL. ${ }^{17,19-21,23-25,28,32}$ Having cancer may improve social and familial relations by increasing the intensity of support and the availability of family caregivers. Conversely, emotional distress can affect the family sphere, and interpersonal relationships are likely to move towards the feeling of ambiguity or fear. Familial structure may be modified, leading to distress within the family. The deterioration of social well-being could be linked with self-image, including hair loss which increases after chemotherapy. ${ }^{33}$ Otherwise, the time since diagnosis may also have an impact on social QoL: in two studies, patients diagnosed 10-15 years earlier presented a better social QoL than those diagnosed 5-9 years before. ${ }^{23,24}$ These findings were similar among families of patients with a head and neck cancer. ${ }^{45}$

Some studies found that professional life was negatively affected in patients. ${ }^{23,39,41,46}$ Another study strengthened this finding by establishing that economic stress was negatively associated with QoL in gynaecological survivors. ${ }^{47}$ Moreover, one paper showed an increase in disability days in patients with breast, lung and gastrointestinal cancers. ${ }^{48}$ These consequences can lead to social isolation and frustration. ${ }^{49}$

Sexual activity, related to body image, was also reduced. ${ }^{29}$ Body image could be an important aspect of our criteria, with the fear of loss of masculinity or femininity and self-image. Other forms of cancer such as gynaecological malignancies also affected patients' sex life. ${ }^{50}$

With regard to cognitive functioning, haematological patients presented several memory and concentration disturbances. ${ }^{28}$ Similar results were found in cancer patients, in whom cognitive deficits were observed after chemotherapy. ${ }^{51}$

Physical, psychological, social and professional problems may be associated with the effects of treatment modalities. QoL was particularly affected in multiple myeloma and chronic lymphoblastic leukaemia patients, treated by chemotherapy or transplantation, in older patients, and in patients with active disease or an advanced stage of disease. Therefore, it would be interesting to conduct a further review with a synthesis of articles that highlight the impact on QoL of treatments recommended for a haematological malignancy.

The potential limitations of this review concern the literature search. Others involve the complexity in interpreting and measuring QoL, the heterogeneity of samples and the loss of subjects during research due to poor medical conditions, death or refusal.

\section{CONCLUSION}

The major strength of our review is the reliability of the selected studies. It shows that haematological cancer patients have a poor QoL or health-related QoL compared with the general population. These findings hold regardless of the type of disease, the treatment modality and the stage of the disease. Generally, we found similar outcomes in other cancers, such as fatigue, which was greater in haematological patients. In theoretical terms, QoL is a complex concept that encompasses various aspects of life and is similar to well-being, so the very meaning of the notion is debatable. Clinically, it is important to analyse QoL early in the course of care. Some types of intervention may prove helpful such as physical programmes, which may be considered as a form of functional care intervention, and other supportive actions, such as psychotherapy which can improve physical and mental functioning.

\section{CONFLICT OF INTEREST}

The authors declare no conflict of interest.

\section{REFERENCES}

1 Bennett JM, Catovsky D, Daniel MT, Flandrin G, Galton DA, Gralnick HR et al. Proposals for the Classification of the Acute Leukaemias French-American-British (FAB) Co-operative Group. Brit J Haematol 1976; 33: 451-458.

2 Ireland R. Haematological malignancies: the rationale for integrated haematopathology services, key elements of organization and wider contribution to patient care. Histopathology 2011; 58: 145-154.

3 Zebrack B. Quality of life of long-term survivors of leukemia and lymphoma. J Psychosoc Oncol 2000; 18: 39-59.

4 Pulte D, Gondos A, Brenner H. Trends in survival after diagnosis with hematologic malignancy in adolescence or young adulthood in the United States, 1981-2005. Cancer 2009; 115: 4973-4979.

5 Lesko LM. Hematological malignancies. Handbook of Psychooncology: Psychological Care of the Patient with Cancer. Oxford University Press: New York NY, USA, 1989; pp 218-231.

6 Aaronson NK, Meyrowitz BE, Bard M, Bloom JR, Fawzy I, Feldstein M et al. Quality of life research in oncology. Past achievements and future priorities. Cancer 1991; 67: 839-843.

7 van Den Beuken-van Everdingen MHJ, de Rijke JM, Kessels AG, Schouten HC, van Kleef $M$, Patijn J. Quality of life and non-pain symptoms in patients with cancer. J Pain Symptom Manag 2009; 38: 216-233.

8 Chao NJ, Tierney DK, Bloom JR, Long GD, Barr TA, Stallbaum BA et al. Dynamic assessment of quality of life after autologous bone marrow transplantation. Blood 1992; 80: 825-830.

9 Ferrell BR, Hassey Dow K, Grant M. Measurement of the quality of life in cancer survivors. Qual Life Res 1995; 4: 523-531.

10 Baker F, Denniston M, Haffer SC, Liberatos P. Change in health-related quality of life of newly diagnosed cancer patients, cancer survivors, and controls. Cancer 2009; 115: 3024-3033

11 Baumann R, Pütz C, Röhrig B, Höffken K, Wedding U. Health-related quality of life in elderly cancer patients, elderly non-cancer patients and an elderly general population. Eur J Cancer Care 2009; 18: 457-465.

12 Wright JG., Swiontkowski MF, Heckman JD. Introducing levels of evidence to the journal. J Bone Joint Surg 2003; 85: 1-3.

13 Strasser-Weippl K, Ludwig H. Psychosocial QOL is an independent predictor of overall survival in newly diagnosed patients with multiple myeloma. Eur $J$ Haematol 2008; 81: 374-379.

14 Courneya KS, Sellar CM, Stevinson C, McNeely ML, Peddle CJ, Friedenreich CM et al. Randomized controlled trial of the effects of aerobic exercise on physical functioning and quality of life in lymphoma patients. J Clin Oncol 2009; 27: 4605-4612.

15 Cull A, Hay C, Love SB, Mackie M, Smets E, Stewart M. What do cancer patients mean when they complain of concentration and memory problems? Brit J Cancer 1996; 74: 1674-1679.

16 Else M, Smith AG, Cocks K, Richards SM, Crofts S, Wade R et al. Patients' experience of chronic lymphocytic leukaemia: baseline health-related quality of life results from the LRF CLL4 trial. Brit J Haematol 2008; 143: 690-697.

17 Frick E, Borasio GD, Zehentner H, Fischer N, Bumeder I. Individual quality of life of patients undergoing autologous peripheral blood stem cell transplantation. Psychooncol 2004; 13: 116-124.

18 Gulbrandsen N, Hjermstad MJ, Wisløff F. Interpretation of quality of life scores in multiple myeloma by comparison with a reference population and assessment of the clinical importance of score differences. Eur J Haematol 2004; 72: 172-180.

19 Heinonen H, Volin L, Uutela A, Zevon M, Barrick C, Ruutu T. Quality of life and factors related to perceived satisfaction with quality of life after allogeneic bone marrow transplantation. Ann Hematol 2001; 80: 137-143.

20 Holzner B, Kemmler G, Kopp M, Nguyen-Van-Tam D, Sperner-Unterweger B, Greil R. Quality of life of patients with chronic lymphocytic leukemia: results of a longitudinal investigation over 1 yr. Eur J Haematol 2004; 72: 381-389.

21 Johnsen AT, Tholstrup D, Petersen MA, Pedersen L, Groenvold M. Health related quality of life in a nationally representative sample of haematological patients. Eur J Haematol 2009; 83: 139-148. 
22 Merli F, Bertini M, Luminari S, Mozzana R, Berté R, Trottini M et al. Quality of life assessment in elderly patients with aggressive non-Hodgkin's Lymphoma treated with anthracycline-containing regimens. Report of a prospective study by the Intergruppo Italiano Linfomi. Haematologica 2004; 89: 973-978.

23 Mols F, Aaronson NK, Vingerhoets AJJM, Coebergh JW, Vreugdenhil G, Lybeert MLM et al. Quality of life among long-term non-Hodgkin lymphoma survivors: a population-based study. Cancer 2007; 109: 1659-1667.

24 Mols F, Vingerhoets AJJM, Coebergh JW, Vreugdenhil G, Aaronson NK, Lybeert MLM et al. Better quality of life among 10-15 year survivors of Hodgkin's lymphoma compared to 5-9 year survivors: a population-based study. Eur J Cancer 2006; 42: 2794-2801.

25 Persson L, Larsson G, Ohlsson O, Hallberg IR. Acute leukaemia or highly malignant lymphoma patients' quality of life over two years: a pilot study. Eur J Cancer Care 2001; 10: 36-47.

26 Rüffer JU, Flechtner $\mathrm{H}$, Tralls $\mathrm{P}$, Josting A, Sieber M, Lathan B et al. German Hodgkin Lymphoma Study Group. Fatigue in long-term survivors of Hodgkin's lymphoma; a report from the German Hodgkin Lymphoma Study Group (GHSG). Eur J Cancer 2003; 39: 2179-2186.

27 Santos FRM, Kozasa EH, Chauffaille Mde L, Colleoni GW, Leite JR. Psychosocial adaptation and quality of life among Brazilian patients with different haematological malignancies. J Psychosom Res 2006; 60: 505-511.

28 Shanafelt TD, Bowen D, Venkat C, Slager SL, Zent CS, Kay NE et al. Quality of life in chronic lymphocytic leukaemia: an international survey of 1482 patients. Brit $J$ Haematol 2007; 139: 255-264.

29 Sherman AC, Coleman EA, Griffith K, Simonton S, Hine RJ, Cromer J et al. Use of a supportive care team for screening and preemptive intervention among multiple myeloma patients receiving stem cell transplantation. Support Care Cancer 2003 11: $568-574$.

30 Smith SK, Zimmerman S, William CS, Zebrack BJ. Health status and quality of life among non-Hodgkin lymphoma survivors. Cancer 2009; 115: 3312-3323.

31 Vallance JKH, Courneya KS, Jones LW, Reiman T. Differences in quality of life between non-Hodgkin's lymphoma survivors meeting and not meeting public health exercise guidelines. Psychooncol 2005; 14: 979-991.

32 Wettergren L, Björkholm M, Axdorph U, Bowling A, Langius-Eklöf A. Individual quality of life in long-term survivors of Hodgkin's lymphoma - a comparative study. Qual Life Res 2003; 12: 545-554.

33 Zittoun R, Achard S, Ruszniewski M. Assessment of quality of life during intensive chemotherapy or bone marrow transplantation. Psychooncol 1999; 8: 64-73.

34 Shipp MA, Harrington DP, Anderson JR, Armitage JO, Bonadonna G, Brittinger G et al. A predictive model for aggressive non-Hodgkin's lymphoma. New Engl J Med 1993; 329: 987-994.

35 Flechtner H, Rüffer JU, Henry-Amar M, Mellink WA, Sieber M, Fermé C et al. Quality of life assessment in Hodgkin's disease: a new comprehensive approach. First experiences from the EORTC/GELA and GHSG trials. EORTC Lymphoma Cooperative Group. Groupe D'Etude des Lymphomes de L'Adulte and German Hodgkin Study Group. Ann Oncol 1998; 9: S147-S154.

36 Jones LW, Eves ND, Peterson BL, Garst J, Crawford J, West MJ et al. Safety and feasibility of aerobic training on cardiopulmonary function and quality of life in postsurgical nonsmall cell lung cancer patients: a pilot study. Cancer 2008; 113: 3430-3439.
37 Steinsbekk A, Adams J, Sibbritt D, Johnsen R. Complementary and alternative medicine practitioner consultations among those who have or have had cancer in a Norwegian total population (Nord-Trøndelag Health Study): prevalence, sociodemographics and health perceptions. Eur J Cancer Care 2010; 19: 346-351.

38 Miltényi Z, Magyari F, Simon Z, Illés Á. Quality of life and fatigue in Hodgkin's lymphoma patients. Tumori 2010; 96: 594-600.

39 Oldervoll LM, Kaasa S, Knobel H, Loge JH. Exercise reduces fatigue in chronic fatigued Hodgkins disease survivors--results from a pilot study. Eur J Cancer 2003; 39: 57-63.

40 Theobald DE. Cancer pain, fatigue, distress, and insomnia in cancer patients. Clin Cornerstone 2004; 6: S15-S21.

41 Fortner BV, Stepanski EJ, Wang SC, Kasprowicz S, Durrence HH. Sleep and quality of life in breast cancer patients. J Pain Symptom Manag 2002; 24: 471-480.

42 Ivanauskiene R, Kregzdyte R, Padaiga Z. Evaluation of health-related quality of life in patients with breast cancer. Medicina (Kaunas) 2010; 46: 351-359.

43 Voogt E, van der Heide A, van Leeuwen AF, Visser AP, MPHD Cleiren, Passchier J et al. Positive and negative affect after diagnosis of advanced cancer. Psychooncol 2005; 14: 262-273.

44 McNeely ML, Campbell KL, Rowe BH, Klassen TP, Mackey JR, Courneya KS. Effects of exercise on breast cancer patients and survivors: a systematic review and meta-analysis. Can Med Assoc J 2006; 175: 34-41.

45 Kaplan BE, Hurley FL. Head and neck cancer: a threat to life and social functioning. Soc Work Health Care 1979; 5: 51-58.

46 Miller JJ, Frost MH, Rummans TA, Huschka M, Atherton P, Brown P et al. Role of a medical social worker in improving quality of life for patients with advanced cancer with a structured multidisciplinary intervention. J Psychosoc Oncol 2007; 25: 105-119.

47 Ell K, Xie B, Wells A, Nedjat-Haiem F, Lee PJ, Vourlekis B. Economic stress among low-income women with cancer: Effects on quality of life. Cancer 2008; 112: 616-625.

48 Kroenke K, Theobald D, Wu J, Loza JK, Carpenter JS, Tu W. The association of depression and pain with health-related quality of life, disability, and health care use in cancer patients. J Pain Symptom Manag 2010; 40: 327-341.

49 Persson L, Hallberg IR, Ohlsson O. Survivors of acute leukaemia and highly malignant lymphoma -- retrospective views of daily life problems during treatment and when in remission. J Adv Nurs 1997; 25: 68-78.

50 Dunberger G., Lind H, Steineck G, Waldenström AC, Nyberg T, Al-Abany M et al. Fecal incontinence affecting quality of life and social functioning among longterm gynecological cancer survivors. Int J Gynecol Cancer 2010; 20: 449-460.

51 Schagen SB, Vardy J. Cognitive dysfunction in people with cancer. Lancet Oncol 2007; 8: 852-853

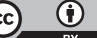

This work is licensed under a Creative Commons Attribution 4.0 International License. The images or other third party material in this article are included in the article's Creative Commons license, unless indicated otherwise in the credit line; if the material is not included under the Creative Commons license, users will need to obtain permission from the license holder to reproduce the material. To view a copy of this license, visit http://creativecommons.org/licenses/ by/4.0/ 